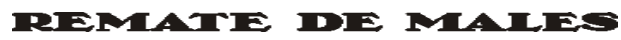

Campinas-SP, v.40, n.2, pp. 546-562, jul./dez. 2020

\title{
Paixão e filologia
}

\section{Passion and Philology}

\section{Davi Pessoa ${ }^{1}$}

Resumo: Este artigo aborda a intempestiva relação entre crítica e linguagem que emergiu já na juventude de Pasolini, a qual será uma constante mutável por toda sua breve vida. Giorgio Agamben aponta que o jovem Pasolini não subjuga o dialeto friulano à língua constitucional, pois deseja dizer com o dialeto coisas elevadas, difíceis, com maior frescor e potência. Assim, a crítica operada por Pasolini mobilizou eruptivos debates, nos quais colocava em choque a língua como inventum (língua institucional) e a língua como inventio (língua-poesia), para desse confronto insurgir-se uma filologia crítica e inventiva. Palavras-chave: filologia; língua; dialeto.

\begin{abstract}
This article addresses the untimely relationship between criticism and language that emerged in Pasolini's youth, which will be a changeable constant throughout his brief life. Giorgio Agamben points out that the young Pasolini does not subdue the Friulian dialect to the constitutional language, as he wants to say with the dialect high, difficult things, with greater freshness and power. Thus, the criticism operated by Pasolini mobilized eruptive debates, in which language shocked as inventum (institutional language) and language as inventio (language-poetry), for this confrontation to arise a critical and inventive philology.
\end{abstract}

Keywords: Philology; Language; Dialect.

Qual seria o gesto intempestivo de Pier Paolo Pasolini entre crítica, língua e linguagem, surgido em sua juventude, e que se fará presente em toda a sua breve vida? A crítica mobilizada por Pasolini orbita muitos universos e traz muitas forças eruptivas. Nela há sempre o confronto

${ }^{1}$ Professor Adjunto de Língua e Literatura Italiana da Universidade Estadual do Rio de Janeiro (UERJ), Brasil: <pessoatradutor@gmail.com>. 
entre a língua como inventum (língua institucional) e a língua como inventio (língua-poesia). De tal duelo emerge uma filologia amorosa, crítica e inventiva, sobre a qual irei me debruçar ao longo deste percurso.

Para onde vai o começo, quando o pensamento se põe a caminhar?

Giorgio Agamben, em maio de 2019, profere uma série de conferências no Palazzo Serra di Cassano, em Nápoles. Na conferência intitulada "Arqueologia", o filósofo busca, como ele mesmo aponta, dar novas considerações à noção de arqueologia. De acordo com ele:

\begin{abstract}
Não se trata, naturalmente, simplesmente de um problema de método, no sentido comum da palavra, quase sempre se entende o método como algo que precede a pesquisa, e, ao mesmo tempo, não pode ser separado da pesquisa, assim como não existe uma lógica que vale para todo argumento, assim não existe um método válido para todo argumento. [...] Não é possível separar o trajeto do pensamento a ser percorrido. O pensamento é em si mesmo, poderíamos dizer, uma odologia, um caminho em direção a si mesmo. Há uma bela definição que vem de Aristóteles, a qual diz que a Natureza é um caminho em direção a si mesma. Diria que o pensamento é sempre um caminho em direção a si mesmo. Não se trata de um caminho de um ponto $\mathrm{A}$ a um ponto B. Não se trata de uma linha. Heidegger, quando havia projetado a edição completa de suas obras, quis colocar como epígrafe: "caminhos, não obra!" (AGAMBEN, 2019a, [s.p.]). ${ }^{2}$
\end{abstract}

Assim, tal caminho não é estável e linear, visto que a arqueologia sempre evidencia um momento destrutivo operado pela tradição, a qual, toda vez que nos transmite algo, soterra ao mesmo tempo muitas camadas temporais. A arqueologia evidencia, portanto, um momento destrutivo, mas também faz emergir um caráter destrutivo, ao modo de Benjamin, cuja premissa, como se sabe, é: abrir espaço para que se possa respirar ar puro. Benjamin, portanto, não deixará de referir-se ao caráter destrutivo operado pela juventude e pela alegria de Nietzsche. Desse modo, ainda seguindo algumas pegadas de Agamben (2019a, [s.p.]), a "arqueologia

\footnotetext{
2 "Non si tratta, naturalmente, semplicemente di un problema di metodo, nel senso comune della parola, spesso si intende il metodo come qualcosa che precede la ricerca e, allo stesso tempo, non può essere separato dalla ricerca, così come non esiste una logica che vale per ogni argomento, così non esiste un metodo valido per ogni argomento. [...] Non è possibile separare il sentiero dal pensiero da percorrere. Il pensiero è in se stesso, si potrebbe dire, un'odologia, un cammino verso se stesso. C'è una bella definizione che viene da Aristotele, la quale dice cha la natura è in cammino verso se stessa. Direi che il pensiero è sempre un cammino verso se stesso. Non si tratta di un cammino da un punto A a un punto B. Non si tratta di una linea. Heidegger, quando aveva pianificato l'edizione completa delle sue opere, aveva voluto metterci come epigrafe: 'sentieri, non opere!." Todas as traduções do italiano, quando não há indicação diferente, são nossas.
} 
tem a ver também com a possibilidade: a arqueologia é a pesquisa de um possível no passado", quando nos relembra que Henri Bergson, em 1927, não podendo ir receber o prêmio Nobel de Literatura, em Estocolmo, por causa de um reumatismo, escreve o texto chamado "O possível e o Real":

O possível é algo que precede o Real - a possibilidade das coisas precede a sua existência - o possível é nada mais que o Real mais um ato da mente, o qual logo que é colocado em prática é lançado ao passado - apenas no momento em que uma obra é criada, ela se torna retroativamente e respectivamente possível. O estatuto do possível é o futuro anterior. A respeito da obra: ela teria sido possível no mesmo instante em que terá sido produzida (AGAMBEN, 2019a, [s.p.]). ${ }^{3}$

Eis uma grande questão: Como introduzir o possível no passado?

Uma das possibilidades apontadas por Agamben - e, também, por Pasolini - é caminhar em direção ao passado, para reencontrar nele um lugar para o possível, e, ao mesmo tempo, para que este venha habitar o presente. A arqueologia, no entanto, não é um mero retorno ao passado. Ou ainda, não tem a ver com a origem, mas com o ponto de insurgência, o qual não desiste de confrontar-se com a tradição histórica. E na guerra civil entre a lógica, que postula a lei universal, e a analogia, que vivencia as singularidades, encontra-se o lapsus.

Pasolini, durante uma entrevista, em Nova Iorque, em 1969, com Giuseppe Cardillo, nos relata um lapsus: diz que todos os anos ia com sua mãe para o Friul. Ele narra que, naquele período:

Enquanto escrevia versos italianos, agora não mais de tipo petrarquista, eleito, tradicional etc. - como [ele] mesmo escrevia até [seus] 17, 18 anos -, mas influenciado por poetas herméticos da época, porque logo após a primeira leitura fundamental de Rimbaud e dos simbolistas, comecei a ler também os outros poetas de então, de Gatto a Penna etc. etc. Enquanto escrevia alguns versos italianos, ouvi da varanda da casa de campo de minha mãe ecoar do quintal a palavra rosada, que significa orvalho [rugiada]; e foi uma iluminação. [...] Ao ouvir aquela palavra me veio imediatamente a ideia de escrevê-la, de usar tal palavra. E escrevi os primeiros versos nos quais havia a palavra rosada, que havia esquecido. No dia seguinte escrevi meu primeiro poema em língua

\footnotetext{
3 "L'archeologia è la ricerca di un possibile nel passato [...]. Il possibile è qualcosa che precede il Reale - la possibilità delle cose precede la loro esistenza - il possibile non è altro che il Reale più un atto della mente, che appena si è prodotto lo respinge dietro nel passato. [...] Solo nel momento in cui l'opera viene creata, essa diviene retrospettivamente o retroattivamente possibile. E non lo sarebbe se non fosse stata reale. Lui dice una cosa interessante, dice che lo statuto del possibile è il futuro anteriore. Cioè, dell'opera si dovrebbe dire che essa sarà stata possibile una volta che sarà stata prodotta."
} 
friulana. Agora, usava essa língua friulana, precisamente, porque era aquela coisa que dizia Valéry: Uma hesitação prolongada entre o sentido e o som, isto é, não era nem sentido nem som, era algo que estava entre as duas coisas, era uma língua para a poesia. Era a língua da poesia que se tornava consciente de si mesma, e estava fisicamente, materialmente em minhas mãos. Então, isso descarta, como dizia antes, a ideia de que essa língua fosse realista. Era o máximo da ambiguidade (PASOLINI, 2005, pp. 38-39).4

O lapsus, promovido pelo esquecimento, coloca um grande problema para Pasolini (2005, p. 38), ou seja, o de como sair da dicotomia estável entre língua e dialeto, ou ainda, da dicotomia dos simbolistas franceses, cujo postulado poético se concentrava sobre dois polos, como ele nos aponta: "A poesia é o conteúdo da própria poesia, e a poesia tem uma língua específica, uma língua que não é decorativa nem referencial, mas que é a própria consciência da linguagem poética". ${ }^{5}$ Portanto, como fazer com que esses polos se choquem, para a partir do confronto irromper-se um terceiro incluído? Ainda: como desativar a lógica da dicotomia, da contradição, para pôr em cena a bipolaridade e a contraditoriedade posta em jogo pela analogia? Pasolini acrescenta: "Então me encontrava diante dessa poética que para mim era extremamente sugestiva e que era puramente literária, e que implicava uma autonomia da literatura e uma totalidade e uma pureza da poesia que não tinha nada de político" (p. 38). ${ }^{6}$

\footnotetext{
4 "Un giorno, mentre scrivevo versi italiani, ormai non più di tipo petrarchistico, eletto, tradizionalistico, ecc., ecc., ma influenzato dai poeti ermetici dell'epoca, perché in seguito dopo la prima lettura fondamentale di Rimbaud e dei simbolisti, ho cominciato a leggere anche gli altri poeti del tempo, da Gatto a Penna, eccetera eccetera, mentre scrivevo dei versi italiani, ho sentito dal ballatoio della casa di campagna di mia madre risuonare nel cortile la parola rosada, che vuol dire 'rugiada'; ed è stata un'illuminazione, una di quelle idee, così come la mela che cade in testa allo scienziato. A sentire quella parola m'è venuta immediatamente l'idea di scrivere, di usare questa parola. E ho scritto dei primi versi in cui c'era questa parola rosada, che ho dimenticato. Il giorno dopo ho scritto la mia prima poesia in lingua friulana. Ora io questa lingua friulana la usavo appunto perché era quella cosa che diceva Valéry: 'Une hésitation prolongée entre le sens et le son', cioè non era né senso né suono, era qualcosa che stava tra le due cose, era una lingua per la poesia. Era la lingua della poesia che si rendeva cosciente a se stessa, ed era fisicamente, materialmente nelle mie mani. Ora questo esclude, come dicevo in principio, l'idea che questa lingua fosse realistica. Era il massimo dell'ambiguità."

5 "La poesia è il contenuto della poesia, e la poesia ha una lingua che le è specifica; una lingua che non è decorativa né referenziale ma che è la coscienza stessa del linguaggio poetico."

6 "Allora io mi trovavo di fronte a questa poetica che per me era estremamente suggestiva e che era puramente letteraria, e che implicava un'autonomia della letteratura e un'assolutezza e una purezza della poesia che non aveva niente di politico."
} 
Se em todo caminho há sempre um passo para trás, então, um novo começo: Sebastiano Timpanaro, filólogo e crítico literário italiano, decidiu renunciarà carreira universitária, mas sem abrir mão de um estudo singular, agora fora do espaço institucional, sobre filologia latina e grega e sobre literatura italiana, além de ter aprofundado suas pesquisas a respeito da psicanálise de Freud. Escreveu, entre outros livros, La filologia di Giacomo Leopardi (1955), La genesi del metodo del Lachmann (1963) e Il lapsus freudiano (1975). Timpanaro seguia, em suas escavações arqueológicas, os vestígios do método de Karl Lachmann, cuja finalidade era encontrar errâncias históricas que pudessem indicar um parentesco entre textos, que por sua vez indicaria um possível arquétipo, e não a reconstrução do texto autógrafo (já que por vezes este vem a faltar). Timpanaro, assim, buscava algo que não existe enquanto origem, fazendo emergir de suas leituras um ponto de insurgência, ou um terceiro incluído, permitindo-lhe ordenar os textos cotejados numa determinada linhagem.

Em 1975, lançou uma tese muito irreverente em Il lapsus freudiano, que tentarei, aqui, relacionar com os procedimentos de Pasolini, quando este se põe à escuta do significante rosada. A tese de Timpanaro seria a seguinte, em poucas palavras: os filólogos analisam os lapsus que os copistas realizam. Uma coisa é o erro da cópia de um texto que está diante dos olhos do copista; outra coisa é o erro de memória diante de uma palavra ou frase aprendida muito tempo antes (destes casos se ocupou, como se sabe, Freud). No entanto, não podemos esquecer que copistas antigos não copiavam os textos palavra por palavra, mas de memória. Então, entre a leitura e a cópia, nesse intervalo de tempo, o lapsus pode acontecer. Aqui também se encontra a grandiosidade do estudo Psicopatologia da vida cotidiana, de Freud, publicado em 1901. Na Itália, quem leu com atenção o texto de Freud, na perspectiva de Timpanaro, foi o célebre filólogo clássico Giorgio Pasquali, autor de Pagine stravaganti di un filologo (1933), Pagine meno stravaganti (1935), Terze pagine stravaganti (1942), Stravaganze quarte e supreme (1951).

Pasolini, nos últimos anos de vida, cada vez mais se interessava por psicanálise e, em certas entrevistas e ensaios, por vezes se refere a Freud, e o faz - como em relação a tantos teóricos que nomeia - sem dar o crédito a um texto ou livro específico. Porém, tais teóricos sempre reaparecem quando um lapsus entra em cena. O que terá, de fato, lido de Freud? Graças ao importante trabalho de catalogação de Graziella Chiarcossi e de Franco Zabagli, temos agora à nossa disposição o livro La biblioteca di Pier Paolo 
Pasolini (2017), no qual encontramos referência a todos os livros de suas estantes, e muitos deles trazem suas anotações, como em Psicopatologia della vita quotidiana (1971), tradução italiana do estudo de Freud, e Il lapsus freudiano (1975), de Timpanaro. Embora os dois livros tenham sido publicados nos últimos anos de vida de Pasolini, podemos encontrar traços das reflexões de Freud e de Timpanaro nos questionamentos do jovem Pier Paolo. O problema de como enfrentar a autonomia literária dos poetas simbolistas, com sua totalidade e pureza sem nada de político, como ele destaca, ou do choque entre língua nacional e dialetos, produz uma sombra de difícil visualização, que gera certas incompreensões por parte dos leitores que buscam caracterizar com clareza a linguagem de suas obras. Como nos aponta o crítico Raúl Antelo, quando lê o caráter destrutivo de Benjamin: "O caráter destrutivo não tem interesse em ser compreendido. Qualquer tentativa nessa direção é banalmente superficial. Ele não se sente afetado de incompreensão" (ANTELO, 2007, p. 28). Pasolini abre brechas para um terceiro elemento, para uma filologia movida por uma enorme força de fabulação e imaginação, a qual, por vezes, é duramente criticada e combatida por filólogos institucionalizados. ${ }^{7}$

Sobre tal aspecto, da superficialidade presente numa tentativa de compreensão imediata, importante retomar uma carta que Pasolini recebe, em 1965, de Magda Righi, que havia acompanhado uma sua conferência em Bolonha, na sala Bossi, no mesmo ano. Ela lhe confidencia que fez um enorme esforço para entender a sofisticação de certas palavras usadas por ele. E pergunta: "Não é possível expor os problemas e as críticas que dizem respeito à arte com uma linguagem acessível a todos?” (PASOLINI, 1977, p. 259). ${ }^{8}$ O poeta então lhe diz:

Certamente todo problema, mesmo o mais árduo, pode ser simplificado e vulgarizado. No entanto, a simplificação e a vulgarização são profundamente deseducadoras: simplesmente informam a presença de alguns problemas e dão em poucas palavras sua solução (PASOLINI, 1977, p. 259). ${ }^{9}$

\footnotetext{
${ }^{7}$ Sobre tal questão, publiquei o ensaio "Pasolini, vulgo Plauto: traduzibilidades" (PESSOA, 2015).

8 "Non è possibile esporre i problemi e le critiche che riguardano l'arte con un linguaggio accessibile a tutti?"

9 "Certo, ogni problema, anche il più arduo, può essere semplificato e volgarizzato. [...] Ma la semplificazione e la volgarizzazione sono profondamente diseducative: informano semplicemente della presenza di alcuni problemi, e ne danno in parole povere la soluzione." 
A intempestiva relação entre crítica e linguagem surge na juventude de Pasolini e será uma constante mutável em diversos momentos de sua vida. Giorgio Agamben (2019b, p. 7), atento a tal exigência, no prefácio ao livro Pier Paolo Pasolini: $i$ turcs tal Friùl / $i$ turchi in Friuli, aponta que "a questão - a quête - da língua é, a meu ver, o núcleo originário incandescente do qual todos os outros problemas pasolinianos são, por assim dizer, as manifestações eruptivas". ${ }^{10}$ Agamben ressalta que poeta não subjuga o dialeto friulano à língua constitucional, pois deseja dizer com o dialeto coisas elevadas, difíceis, com maior frescor e potência. Assim, a crítica operada por Pasolini, desde muito cedo, mobilizou debates acalorados, nos quais colocava em choque a língua como inventum (língua institucional) e a língua como inventio (língua-poesia), para, a partir do confronto entre elas, emergir uma filologia-crítica intempestiva e inventiva, que será traçada a partir de agora por anotações.

Anotação 1: "Stroligut di cà da l'Aga", de 1944, título da primeira revista da Academiuta di Lenga Furlana, é uma espécie de manifesto voltado aos camponeses. Como nos aponta Agamben, Pasolini inscreve uma epígrafe de Percy Bysshe Shelley ao ensaio "Dialet, lenga e stil", que abre o primeiro número da revista: "Na infância da sociedade todo autor é necessariamente um poeta, porque a própria linguagem é poesia" (PASOLINI, 2019, p. 17). ${ }^{11} \mathrm{O}$ texto-manifesto segue com uma declaração: "Certamente, camponeses, vocês jamais pensaram nas relações que se dão entre as ideias de dialeto, língua e estilo" (p. 64). ${ }^{12}$ Complementa: "Nenhum de vocês saberia escrevê-lo, esse dialeto, e, quase, nem mesmo lê-lo. No entanto, é vivo, e como é vivo!, em suas bocas, nos lábios dos jovens, nos peitos dos garotinhos, e ecoa alegremente de prado em prado, de campo em campo" (p. 64). ${ }^{13}$ E prossegue:

E se alguém tivesse a ideia de escrevê-lo? E de escrevê-lo com a ambição de dizer coisas mais elevadas, difíceis, talvez. E se por acaso alguém tenha tal

\footnotetext{
10 "[...] la questione - la quête - della lingua è, cioè, secondo noi, l'originario nucleo incandescente di cui tutte le altre problematiche pasoliniane sono, per così dire, le manifestazioni eruttive".

" "Nell'infanzia della società ogni autore è necessariamente un poeta, perché il linguaggio stesso è poesia."

${ }_{12}$ "Di certo, paesani, non avete mai pensato ai rapporti che intercorrono fra le idee di 'dialetto', 'lingua' e 'stile."

${ }_{13}$ "Nessuno di voi saprebbe scriverlo, questo dialetto, e, quasi quasi, neanche leggerlo. Ma intanto lui è vivo, e come vivo!, nelle vostre bocche, nella labbra dei giovinetti, nei petti dei giovanotti, e suona allegramente di prato in prato, di campo in campo."
} 
ideia, é bom que a realize, e outros que falam aquele mesmo dialeto, o seguem e o imitam, e assim, um pouco por vez, amontoa-se uma boa quantidade de material escrito, então esse dialeto se torna língua. A língua seria, portanto, um dialeto escrito e usado para exprimir os sentimentos mais elevados e secretos do coração (PASOLINI, 1999, pp. 64-65).14

\section{Ao fim do texto, ele aponta:}

Quando um dialeto se torna língua, todo escritor usa tal língua conforme suas ideias, seu caráter, seus desejos. Em suma, todo escritor escreve e compõe de maneira diferente e cada um tem seu estilo. Este é algo de interior, oculto, privado, e, sobretudo, individual. Um estilo não é nem italiano nem alemão nem friulano, é daquele poeta e basta (PASOLINI, 1999, p. 67). ${ }^{15}$

\section{Essa singularidade será reforçada, anos mais tarde, em 1968, durante} uma entrevista a Jon Halliday:

Estilisticamente sou um pasticheur. Uso o material estilístico mais disparatado: poesia dialetal, poesia decadente, certas tentativas de poesia socialista; há sempre em meus escritos uma contaminação estilística, não tenho um estilo pessoal, completamente inventado por mim, embora possua um estilo reconhecível. Se você lê uma minha página, não demora a reconhecer como minha. Não sou reconhecível porque inventor de uma fórmula estilística, mas pelo grau de intensidade ao qual levo a contaminação (PASOLINI, 2014, p. 49). ${ }^{16}$

\section{Anotação 2: Em "Academiuta di lenga furlana", texto originalmente publicado em Il Stroligut, em 1 de agosto de 1945, Pasolini (1999, p. 75)}

${ }_{14}$ "Ma se a qualcuno venisse quella idea? Voglio dire l'idea di adoperare il dialetto per esprimere i propri sentimenti, le proprie passioni? [...] Ma con l'ambizione di dire cose più elevate, difficili, magari; [...] Se a qualcuno viene quella idea, ed è buono realizzarla, e altri che parlano quello stesso dialetto, lo seguono e lo imitano, e così, un po' alla volta, si ammucchia una buona quantità di materiale scritto, allora quel dialetto diventa 'lingua'. La lingua sarebbe così un dialetto scritto e adoperato per esprimere i sentimenti più alti e segreti del cuore."

15 "Quando un dialetto diventa lingua, ogni scrittore adopera quella lingua conforme le sue idee, il suo carattere, i suoi desideri. Insomma ogni scrittore scrive e compone in maniera diversa e ognuno ha il suo 'stile'. Quello stile è qualcosa di interiore, nascosto, privato, e, soprattutto, individuale. Uno stile non è né italiano né tedesco né friulano, è di quel poeta e basta."

16 "Stilisticamente sono un pasticheur. Adopero il materiale stilistico più disparato: poesia dialettale, poesia decadente, certi tentativi di poesia socialista; c'è sempre nei miei scritti una contaminazione stilistica, non ho uno stile personale, mio, completamente inventato da me, benché possegga uno stile riconoscibile. Se lei legge una mia pagina, non stenta a riconoscerla come mia. Non sono riconoscibile perché inventore di una formula stilistica, ma per il grado di intensità al quale porto la contaminazione e la commistione dei differenti stili."

Remate de Males, Campinas-SP, v.40, n.2, pp. 546-562, jul./dez. 2020 - 553 
defende uma estética do coração, ou seja, o escritor está muito atento ao fato de que a filologia é uma relação afetiva, de amizade, uma philía, com a linguagem. Portanto, não se trata de uma técnica epistêmica, pois a filologia é uma pathologia, e seu pathos recorre ao pathos do legein (verbo grego, do qual se forma logos, que tem a força de produzir tensões, cujos sentidos a partir do indo-europeu são: pôr e depor; depositar; expor e propor, reunir), realizando, assim, "un movimiento doble, que siempre haga la experiencia del acercamiento al mismo tiempo que una experiencia del alejamiento", tal como lemos em Para - la Filología, do filósofo Werner Hamacher (2011, p. 17). ${ }^{17}$ Assim, dessa relação amorosa com a língua friulana poética, Pasolini monta outra temporalidade, cuja força é capaz de colocar em movimento o que se encontrava imóvel no passado:

No nosso Friulano encontramos uma vivacidade, uma nudez, uma cristandade, que podem resgatá-lo de sua desanimadora pré-história poética. [...] Nossa verdadeira tradição, portanto, iremos procurá-la lá onde a história triste do Friul a dissecou, ou seja, o Trecento. [...] A tradição que naturalmente teremos que perseguir se encontra na moderna literatura francesa e italiana, que parece ter alcançado um ponto de extrema consumação de tais línguas; enquanto a nossa ainda pode contar com sua rústica e cristã pureza. Assim, nossa estética não se fecha em si mesma, sendo uma estética do coração, não do cérebro.$^{18}$

Anotação 3: "Sulla poesia dialettale", publicado em Poesia, em outubro de 1947. Logo no início, lê-se uma premissa questionadora, na qual podemos perceber a relação amorosa na amizade pela linguagem e pela palavra, que traduz seu amor pela leitura:

Escrever em dialeto não seria senão uma transposição em versos (em versos "imitados" pela língua) de alguns sentimentos que em língua não são exprimíveis? [...] Seria logo necessária uma definição de tais sentimentos, mas basta dizer que, falsamente ingênuos, neles a consciência de uma espécie de utilidade folclórica é algo como uma civilização à margem, uma civilização

\footnotetext{
${ }_{17}$ “[...] um movimento duplo, que sempre se faça a experiência de aproximação ao mesmo tempo em que realiza uma experiência de distanciamento".

${ }_{18}$ "Nel nostro Friulano noi troviamo una vivezza, e una nudità, e una cristianità che possono riscattarlo dalla sua sconfortante preistoria poetica. [...] La nostra vera tradizione, dunque, andremo a cercarla là dove la storia sconsolante del Friuli l'ha disseccata, cioè il Trecento. [...] La tradizione che naturalmente dovremo proseguire si trova nell'odierna letteratura francese ed italiana, che pare giunta ad un punto di estrema consumazione di quelle lingue; mentre la nostra può ancora contare su tutta la sua rustica e cristiana purezza. Così la nostra estetica non si chiude in se stessa, essendo un'estetica del cuore, non del cervello."
} 
parasitária. [...] Na Itália, há uma centena desses que realizam uma semelhante operação. Mas não é deles que queremos nos ocupar (PASOLINI, 1999, p. 244). ${ }^{19}$

Como se percebe, Pasolini tenta desfazer a noção de representação de língua dialetal originada numa tradição folclórica, movida, portanto, por um espaço geograficamente circunscrito. Há, em questão, uma regressão que não busca uma origem:

Digamos logo que se trataria de um momento instintivo, e deve-se crer, com Freud, que os instintos levam a uma condição anterior, a um regresso: daí o eterno atraso do dialeto. Mas também se deve logo perceber que "instintivo", no nosso caso, corresponda a ingênuo e irracional, ou seja, aos atributos mais flagrantes do romântico. [...] Quando, aqui, falamos de Romantismo, pretendemos nos referir ao mais interior Romantismo, aquele que se pode ligar ao conceito de Gianbattista Vico, ou seja, do homem-criança, aquele que gira em espiral em torno da redescoberta da poesia romança, e que dará, por fim, a poesia "falada" do melhor Pascoli e dos Modernos (PASOLINI, 1999, pp. 245246). ${ }^{20}$

Pasolini (1999, p. 249) parece estar consciente de que havia, em parte da literatura italiana do último Ottocento, uma tendência ao uso do dialeto, porém tal uso ainda recaía numa língua clássica e tradicional, e, por isso, chega a afirmar que é, sobretudo, "em Pascoli que temos um centro de troca entre língua e dialeto; e, não por nada, esse poeta é extraordinariamente popular entre os vernáculos, que são, aliás, em boa parte, pascolinianos". ${ }^{21}$ Ao fim do texto, Pasolini põe uma questão focada

19 "Lo scrivere in dialetto non sarebbe altro che una trasposizione in versi (in versi 'imitati' dalla lingua) di alcuni sentimenti che in lingua non sono esprimibili? [...] Sarebbe necessaria subito una definizione di tali sentimenti, ma basti dire che, falsamente ingenui, in essi la coscienza di una specie di utilità folcloristica è qualcosa come una civiltà in margine, una civiltà parassitaria. [...] Coloro che compiono una simile operazione (li si immagini dentro il quadretto di un mediocre 'macchiaiolo') sono in Italia a centinaia. Ma non è di essi che intendiamo occuparci."

20 "Diciamo subito che si tratterebbe di un momento istintivo, ed è da credere, con Freud, che gli istinti riportino a una condizione anteriore, a un regresso: di qui l'eterno ritardo del dialetto. Ma è pure da notarsi subito come 'istintivo' nel nostro caso corrisponda a ingenuo e a irrazionale, cioè, agli attributi più scoperti del romantico. [...] Quando qui parliamo di Romanticismo, intendiamo riferirci al più interiore Romanticismo, quello che si può riallacciare al concetto vichiano dell'uomo-fanciullo, quello che vortica intorno alla riscoperta della poesia romanza, e che darà infine la poesia 'parlata' del migliore Pascoli e dei Moderni."

21 "[...] nel Pascoli cha abbiamo un centro di scambio tra lingua e dialetto; e non per nulla questo poeta è straordinariamente popolare tra i Vernacoli, che sono anzi, in buona parte, dei Pascoliani”. 
no categórico por que da escrita dialetal: "Afinal, por que escrever em dialeto?" (PASOLINI, 1999, p. 259).22 E esboça uma resposta:

A resposta é mais complexa do que parecem demonstrar as poucas linhas que a contêm: escrever um dialeto intenso não é apenas uma evasão, ou uma aventura, ou, em suma, um retirar-se, mesmo que momentâneo, do empenho moral do que escrever em língua; ele responde a uma necessidade profunda de diversidade (PASOLINI, 1999, p. 259).23

Anotação 4: Em “Dalla lingua al friulano", publicado em Ce fastu?, em 1947, Pasolini (1999, p. 282) argumenta que é entre:

Os termos do "traduzível" e do "intraduzivel" que se movem as mais agudas sugestões de nossa poética friulana; queremos dizer que a ossatura delicada de nosso dialeto-linguagem mesmo no âmbito da língua, ou seja, da traduzibilidade, não se retira de forma alguma dos riscos de indefinição estética, portanto, do intraduzível. ${ }^{24}$

Assim, a poética friulana põe em questão a dicotomia língua-dialeto, com o intuito de problematizar as poéticas que se utilizam de cada um dos polos como resultado de uma dialética entre o que poderíamos chamar, também, de poesia popular e poesia moderna, com o intuito de fazer emergir do confronto uma terceira língua, ou um modo de vir a ser do fantasma da voz, fantasma arcaico e moderno, ao mesmo tempo. Portanto, uma bipolaridade, ou, como Pasolini (1999, p. 252) aponta no texto já citado "Sobre a poesia dialetal": "Retomando uma ideia de [Samuel Taylor] Coleridge, poderíamos dizer que a poesia dialetal (tal como postulada pelos jovens febris de Casarsa) é uma paisagem noturna atingida por um raio de luz". ${ }^{25}$

Anotação 5: Em "Ragioni del friulano", publicado em Il Mattino del popolo, em 2 de novembro de 1948, Pasolini escreve:

\footnotetext{
22 "Infine, perché scrivere in dialetto?"

${ }_{23}$ "La risposta è più complessa di quanto sembrino dimostrare le poche righe che la contengono: scrivere in un dialetto così inteso non è solo un'evasione, o un'avventura, o, insomma, un sottrarsi, sia pur momentaneo, all'impegno morale dello scrivere in lingua; esso risponde a un bisogno profondo di diversità."

24 "Entro i termini del 'traducibile' e dell'intraducibile' che si muovono le più acute suggestioni della nostra poetica friulana; vogliamo dire che l'ossature délicate del nostro dialetto-linguaggio pur nell'ambito della lingua, ossia della traducibilità, non si nega affatto ai rischi dell'indefinitezza estetica, ossia dell'intraducibile..."

25 "Riprendendo un'idea di Coleridge, si potrebbe dire che la poesia dialettale è un paesaggio notturno colpito a un tratto dalla luce."
} 
O bom friulano que por aventura siga essa pequena discussão (que diz respeito, além do mais, à "salvação" de sua língua) deve ter presente, antes de tudo, que, além da lampejante distinção entre "língua falada" e "língua escrita", existe uma ulterior, e maior distinção essencial entre língua literal como inventum e língua como inventio. A primeira é a língua institucional, aquela da qual não só se servem comumente os falantes (os quais, com frequência, põem nela como reagente um coração muito pessoal e, portanto, inventivo), mas, especialmente, os escreventes comuns, ou seja, não poetas; a segunda é a língua anticonstitucional, usada, como vimos, seja pelos falantes numa colorida e dinâmica contaminação com os institutos (daí a evolução da língua), seja pelos escreventes-poetas (PASOLINI, 1999, pp. 298-299). ${ }^{26}$

Pasolini, nesse texto, respondia ao artigo do jovem Bernardino Virgili, que fazia parte da Sociedade Filológica Friulana e cujo artigo havia sido publicado também em Il Mattino del Popolo, em 19 de outubro de 1948; o jovem se demonstrava preocupado com a salvação do friulano como instituição, ou como ato poético. Pasolini (1999, p. 299) lhe diz que:

\begin{abstract}
No primeiro caso, temo que seria fácil cair na abstração e na utopia: as instituições linguísticas são um fato histórico, que requer necessidades sociais, políticas e econômicas às quais responder com aderência vital; enquanto é claro que aqui no Friul desde muitos séculos até hoje essas necessidades não existem e a única razão para manter vivo o friulano como instituição linguística é sentimental ou literária, e não é certamente uma razão suficiente. Da outra parte, eu e meus amigos da Academiuta e todos os que olhem com interesse nosso félibrige, ${ }^{27}$ embora fora do Movimento Popular Friulano e de outros movimentos regionalistas de gosto, porém, muito provinciano, continuam a tomar partido pela Região friulana, esperando que esta consiga criar as necessidades de que falava; mas é uma esperança muito fraca. ${ }^{28}$
\end{abstract}

\footnotetext{
26 "Il buon friulano che per avventura segua questa piccola discussione (che concerne peraltro la 'salvezza' della sua lingua) deve tener presente anzitutto che oltre alla ormai lampante distinzione di 'lingua parlata' e 'lingua scritta' esiste un'ulteriore, più essenziale distinzione tra lingua letterale come inventum e lingua come inventio. La prima è la lingua istituzionale, quella di cui non solo si servono comunemente i parlanti (i quali spesso vi pongono come reagente un cuore molto personale e quindi inventivo) ma in specie gli scriventi comuni, cioè non poeti, la seconda à la lingua anti-costituzionale, adoperata, come abbiamo visto, sia dai parlanti in una colorita e dinamica contaminazione con gli istituti (di qui l'evoluzione della lingua), sia dagli scriventi-poeti."

${ }^{27}$ Movimento dedicado à defesa da língua e cultura da Occitânia, com conexões com os Países Catalães. Sua atuação situa-se especialmente no âmbito literário.

28 "Nel primo caso temo che sarebbe facile cadere nell'astrazione e nell'utopia: le istituzioni linguistiche sono un fatto storico, che richiede necessità sociali, politiche ed economiche a cui rispondere con aderenza vitale; mentre è chiaro che qui in Friuli ormai da molti secoli quelle necessità non esistono el'unica ragione per tenere in vita un friulano come istituzione linguistica è sentimentale o letteraria, e non è certo una ragione sufficiente. D'altra parte io e i miei amici dell'Academiuta e quanti guardino con interesse il nostro félibrige, benché fuori dal Movimento Popolare Friulano e da altri movimenti regionalistici dal gusto però molto provinciale, continuano a parteggiare per la Regione friulana, sperando che questa concorra a creare quelle necessità di cui si parlava; ma è una speranza assai debole."
}

Remate de Males, Campinas-SP, v.40, n.2, pp. 546-562, jul./dez. 2020 - 557 
Pier Paolo, portanto, parece pôr em operação um princípio de anarquia, que busca desativar tanto a origem como o comando (significância bipolar proveniente do termo grego arché). Reiner Schürmann, em Dos princípios à anarquia (1982), distingue original de originário. O primeiro tem a ver com o princípio histórico, e o segundo com um princípio a-histórico, um puro vir à presença, o qual não comanda nem determina o devir histórico. A arché não coincide nem com o original nem tampouco com o originário, mas se situa na soleira entre um e outro, entre a origem no sentido forte do termo e a tradição histórica. Como se colocar nesse hiato? Pasolini (1999, pp. 300-301) responde a tal questão por via da invenção: "Do ponto de vista linguístico, o que importa é inventar, aquilo que vale para o friulano de Casarsa como para aquele de San Daniele, para o italiano como para o chinês". ${ }^{29}$

Anotação 6: Em "Motivi vecchi e nuovi per una poesia friulana non dialettale”, publicado em Il Tesaùr, 1949, irá reforçar a exigência de implicar-se diante de uma paisagem, e não somente como paisagem que é apenas contemplada. Contra a fenomenologia da percepção, na qual o sujeito não se implica, não entra na paisagem como partícipe de uma luta - visto que aquilo que vê não o vê, muito menos se vê vendo na paisagem -, Pasolini (1999, p. 319) põe em jogo, a meu ver, a arqueologia da sensação, ou seja, a paisagem que vejo também me vê, e nesse confronto o sujeito se transforma: "E eis, portanto, novos itinerários geográficos, aliás, topográficos. O estrangeiro não irá mais visitar o forte de Osoppo, mas irá ver os jovens que passeiam sob a lua". ${ }^{\circ}$ Paisagem noturna atingida por um raio de luz, ou ainda: obscuridade igual à luz, como lemos no primeiro canto do "Inferno" de La divina mimesis.

Em “Poesia d'oggi”, publicado em La Panarie, em 1949, Pasolini (1999, pp. 322-323) argumenta:

Posso dizer que, de um ponto de vista estritamente linguístico, meu friulano de 1942 era algo diferente de um dialeto, visto que ambicionava, para usar uma minha terminologia de então, a uma minha linguagem privada e hermética (não obscura!) na qual pudesse perseguir puros fantasmas poéticos, obstinado por um único sentimento: a nostalgia. Era, por outro lado, "dialeto" enquanto havia solicitado de mim uma forma de regressão linguística, em direção a um

\footnotetext{
29 "Dal punto di vista linguistico ciò che importa è inventare, cosa che vale per il friulano di Casarsa come per quello di San Daniele, per l'italiano come per il cinese."

30 "Ed ecco dunque nuovi itinerari geografici, anzi, topografici. Lo straniero non andrà più a visitare il forte di Osoppo, ma verrà a vedere i giovanotti casarsesi che passeggiano sotto la luna."
} 
léxico túrgido de vida não manifesta, léxico virgem, imediato e imprudente, com vocalidades delicadas e penumbras nas quais reconhecia, já dada, aquela que podia ser a musicalidade pura do simbolismo; assim, de um regresso a uma recuperação até mesmo muito alucinante de sugestões literárias mais avançadas, o intervalo era brevíssimo. Eis porque meus versos não foram e não são entendidos pelos friulanos. ${ }^{31}$

Tudo isso movido por uma filologia - e não pela Filológica ${ }^{32}$-, que Pasolini tanto amava: uma filologia sem filólogos. Ou, ainda, como anota: "Certos procedimentos técnicos da poesia italiana e francesa mais moderna, atribuição analógica, valor da rima fora da forma fechada, aproximações puramente fantásticas e certas urgências sentimentais, logo se tornaram familiares a esses jovens" (PASOLINI, 1999, p. 326). ${ }^{33}$ Ao contrário da paisagem do Friul ocidental, não como dado folclórico, mas "como dado paisagístico amoroso, [o Friul] é quase o motivo dominante de nossa poesia!" (p. 328). ${ }^{34}$

Em última análise, Pasolini, a partir da figura da sombra projetada por paisagens muito heterogêneas, abre um confronto com a conhecida concepção de signo da semiologia moderna - tal como apresentado no Curso de linguística geral, de Saussure -, ou, ainda, lança uma sombra justamente naquilo que denunciaria a fratura originária entre S/s. A barra, em sua suposta relação entre significante e significado, resiste à significação. Ou ainda: impõe-se o muro da tradição, caracterizado por uma fratura metafísica da presença, para a qual tudo aquilo que vem à presença, vem à presença como lugar de um diferimento e de uma exclusão, no sentido de que seu manifestar-se é, ao mesmo tempo, um

\footnotetext{
31 "Posso dire, da un punto di vista strettamente linguistico, che il mio friulano del 1942 era qualcosa di diverso da un dialetto, in quanto io ambivo, per usare la mia terminologia di allora, a un mio linguaggio privato ed ermetico (non oscuro!) dove perseguire puri fantasmi poetici ossessionato da un sentimento solo: la nostalgia. Era d'altra parte 'dialetto' in quanto aveva richiesto da me una forma di regresso linguistico, verso un lessico turgido di vita inespressa, vergine, immediato e imprudente, con vocalità delicate e penombre nelle quali io ravvisavo, già data, quella che poteva essere la musicalità pura del simbolismo; dal regresso, dunque, a un recupero fin troppo fulmineo delle suggestioni letterarie più avanzate l'intervallo era brevissimo. Ecco perché quei miei versi di allora non furono e non sono capiti dai friulani."

${ }^{32}$ A Sociedade Filológica Friulana é uma associação que tem como objetivo estudar a língua e cultura friulana, fundada em Gorizia, em 23 de novembro de 1919.

33 "Certi procedimenti tecnici della poesia italiana e francese più moderna, attribuzione analogica, valore della rima fuori dalla forma chiusa, accostamenti puramente fantastici, e certe urgenze sentimentali divennero subito familiari a questi ragazzi."

34 “[...] come dato paesaggistico-amoroso è quasi il motivo dominante della nostra poesia!".
} 
ocultar-se, e o seu ser presente, uma falta. O que acabo de lhes dizer é uma das teses centrais do estudo de Agamben (2012) em Estâncias. Talvez por essa razão, tenha se interessado por certa psicanálise, encontrando-se muito próximo ao modo de articulação dela por Lacan, na qual a abertura à significação não se dá apenas entre a cadeia de significantes, como resistência e confronto ao círculo encerrado do logos, visto que:

A experiência da língua de que eu falo aqui não é a experiência de tal ou tal proposição significante, de tal enunciado no interior da linguagem, mas experiência da linguagem mesma, do puro fato de que se fale, de que haja linguagem. Ora, o que pode ser tal experiência, e como é ela concebível? Como fazer a experiência não de um objeto nomeado ou de um enunciado, mas da língua mesma? O que quer dizer se lembrar de que se diga? O que está em jogo nessa estranha memória? E o que significa ter esquecido não tal ou tal proposição que se disse, mas que se diga? (AGAMBEN, 2018, p. 7).35

Tal passagem se lê em Experimentum linguae - conferência proferida, em 25 de maio de 1990, por Giorgio Agamben, durante o colóquio "Lacan avec les Philosophes", organizado pelo Collège International de Philosophie de Paris.

Pasolini, portanto, parece nos colocar diante de um impasse - que também se tornou o impasse vivido por ele, impasse vivido e inscrito no corpo, durante os anos do fascismo - que é, ao mesmo tempo, e por mais estranho que nos possa parecer, abertura; o experimentum é importante, como aponta Agamben (2018, p. 8), "porque nele nós fazemos a experiência de uma pura possibilidade. É a experiência graças à qual podemos dizer: eu posso. É o dom e o advento de uma potência", ${ }^{6}$ mesmo quando o significante "totalitarismo" busca aniquilar todas as potências humanas. $\mathrm{O}$ experimentum linguae, portanto, é também um experimentum potentiae. Em La divina mimesis, lê-se: "Você sabe o que é a língua culta; sabe o que

\footnotetext{
35 "L'expérience de la langue dont je parle ici n'est pas expérience de telle ou telle proposition signifiante, de tel énoncé à l'intérieur du langage, mais expérience du langage même, du pur fait que l'on parle, qu'il y ait du langage. Or, que peut être une telle expérience, et comment est-elle concevable? Comment faire l'expérience non pas d'un objet nommé ou d'un énoncé, mais de la langue même? Que veut dire se rappeler qu'on dise? Qu'est-ce qui est en jeu dans cette étrange mémoire? Et que signifie avoir oublié non pas telle ou telle proposition qu'on a dite, mais qu'on dise?"

36 “[...] parce que nous y faisons l'expérience d'une pure possibilité. C'est l'expérience grâce à laquelle nous pouvons dire je peux. C'est le don et l'événement d'une puissance".
} 
é aquela vulgar. Como poderia fazer uso delas? São ambas, agora, uma única língua: a língua do ódio" (PASOLINI, 2006, p. 22).37

A filologia-crítica intempestiva e inventiva de Pasolini busca, sobretudo, o amor pelo estudo, e este - em latim, studium - é definido como o grau máximo do desejo. $\mathrm{O}$ experimentum linguae de Pier Paolo Pasolini não se dá sem pathos. Em última análise, não há filologia sem paixão, e do encontro entre elas emerge o experimentum potentiae não apenas de sua poética friulana, mas também de seu percurso artístico fragmentado e filologicamente inventivo.

\section{$\overline{\text { REFERÊNCIAS }}$}

AGAMBEN, Giorgio. Estâncias: a palavra e o fantasma na cultura ocidental. Trad. Selvino José Assmann. Belo Horizonte: Editora UFMG, 2012.

AGAMBEN, Giorgio. Experimentum linguae: a experiência da língua. Trad. Cláudio Oliveira. Rio de Janeiro: Circuito, 2018.

AGAMBEN, Giorgio. L'Archeologia. [Conferência.] Palazzo Serra di Cassano, Nápoles, maio 2019a. Disponível em: <https://www.youtube.com/watch?v=Qkvlp4hUpL4>. Acesso em: 5 maio 2020.

AGAMBEN, Giorgio. [Prefazione.] In: PASOLINI, Pier Paolo. (Acura di Graziella Chiarcossi) Pier Paolo Pasolini. I Turcs tal Friul. I Turchi in Friuli. Macerata: Quodlibet, 2019b, pp. 7-24.

ANTELO, Raúl. Tempos de Babel: anacronismo e destruição. São Paulo: Lumme Editor, 2007.

HAMACHER, Werner. Para - la Filología / 95 tesis sobre la filología. Trad. de Laura S. Cangati. Buenos Aires: Miño y Dávila, 2011.

PASOLINI, Pier Paolo. Le belle bandiere. Roma: L’Unità/Editori Riuniti, 1977.

PASOLINI, Pier Paolo. (A cura di Walter Siti e Silvia De Laude) Saggi sulla letteratura e sull'arte. Milano: Arnoldo Mondadori Editore, 1999.

PASOLINI, Pier Paolo. (A cura di Luigi Fontanella) Pasolini rilegge Pasolini: intervista con Giuseppe Cardillo. Milano: Archinto, 2005.

PASOLINI, Pier Paolo. La divina mimesis. Milano: Oscar Mondadori, 2006.

37 “Tu sai cos'è la lingua colta; e sai cos’è quella volgare. Come potrei farne uso? Sono entrambe ormai un'unica lingua: la lingua dell'odio."

Remate de Males, Campinas-SP, v.40, n.2, pp. 546-562, jul./dez. 2020 - 561 
PASOLINI, Pier Paolo. Pasolini su Pasolini: conversazioni con Jon Halliday. Parma: Ugo Guanda Editore, 2014.

PASOLINI, Pier Paolo. (A cura di Graziella Chiarcossi) Pier Paolo Pasolini. I Turcs tal Friul. I Turchi in Friuli. Prefazione di Giorgio Agamben. Macerata: Quodlibet, 2019.

PESSOA, Davi. Pasolini, vulgo Plauto: traduzibilidades. Revista Diálogos Mediterrâneos, n. 9, 2015, pp. 89-98. Disponível em: <http://www.dialogosmediterranicos.com.br/ index.php/RevistaDM/article/view/186>. Acesso em: 23 nov. 2020.

SCHÜRMANN, Reiner. Dai principi all'anarchia: essere e agire in Heidegger. Trad. Gianni Carchia. Bologna: Il Mulino, 1995.

Recebido: 7/5/2020

Aceito: $13 / 8 / 2020$

Publicado: 26/11/2020

Remate de Males, Campinas-SP, v.40, n.2, pp. 546-562, jul./dez. 2020 - 562 